\title{
Potential life-years gained over a 5-year period by correcting DOPPS-identified modifiable practices in haemodialysis: results from the European MONITOR-CKD5 study
}

\author{
Christian Combe ${ }^{1}$, Johannes Mann², David Goldsmith ${ }^{3}$, Frank Dellanna ${ }^{4}$, Philippe Zaoui ${ }^{5}$, Gérard London ${ }^{6}$, \\ Kris Denhaerynck ${ }^{7,8}$, Andriy Krendyukov ${ }^{9}$, Ivo Abraham ${ }^{7,10^{*}}$ and Karen MacDonald ${ }^{7}$
}

\begin{abstract}
Background: DOPPS reported that thousands of life-years could be gained in the US and Europe over 5 years by correcting six modifiable haemodialysis practices. We estimated potential life-years gained across 10 European countries using MONITOR-CKD5 study data.

Methods: The DOPPS-based target ranges were used, except for haemoglobin due to label changes, as well as DOPPS-derived relative mortality risks. Percentages of MONITOR-CKD5 patients outside targets were calculated. Consistent with the DOPPS-based analyses, we extrapolated life-years gained for the MONITOR-CKD5 population over 5 years if all patients were within targets.
\end{abstract}

Results: Bringing the 10 MONITOR-CKD5 countries' dialysis populations into compliance on the six practices results in a 5-year gain of 97,428 patient-years. In descending order, survival impact was the highest for albumin levels, followed by phosphate levels, vascular access, haemoglobin, dialysis adequacy, and interdialytic weight gain.

Conclusions: Optimal management of the six modifiable haemodialysis practices may achieve $6.2 \%$ increase in 5-year survival.

Trial Registration: NCT01121237. Clinicaltrials.gov registration May 12, 2010 (retrospectively registered).

Keywords: Haemodialysis, Modifiable haemodialysis practices, Life-years, Biosimilar epoetin alfa, Anaemia

\section{Background}

The Dialysis Outcomes and Practice Patterns Study (DOPPS) [1] reported [2] that an additional 143,617 patient life-years could be gained in the United States over a 5-year period if six modifiable haemodialysis practices were brought into best practice compliance. Four of the six modifiable haemodialysis practices (dialysis dose, phosphate control, improved anaemia, and partial correction of serum albumin) are supported by published guidelines [3-6] while reduced inter-dialytic weight gain $[7,8]$ and reduced use of catheters for

\footnotetext{
* Correspondence: iabraham@matrix45.com

${ }^{7}$ Matrix45, Tucson, AZ, USA

${ }^{10}$ University of Arizona College of Pharmacy and College of Medicine,

Tucson, AZ, USA

Full list of author information is available at the end of the article
}

vascular access [9-12] have been linked to mortality. These analyses were replicated for Belgium [13], Spain [14], France [15] and Sweden [16], except that albumincorrected serum calcium was substituted for intradialytic weight gain. Here, we present a simulation of potential life-years gained by correcting these six practices across 10 European countries using data from the MONITORCKD5 study.

\section{Methods}

MONITOR-CKD5, a real-world, prospective, observational study on the treatment patterns and associated outcomes of renal anaemia management with Sandoz epoetin alfa biosimilar (commercially available as Binocrit $^{\circ} /$ Epoetin Alfa $\mathrm{Hexal}^{\circ}$; hereafter Binocrit ${ }^{\circ}$ ), included an evaluable sample of 2023 CKD5 patients from 114 
centres in 10 European countries: Austria (6 centres), France (35), Germany (45), Italy (21), Poland (7), Romania (14), Slovenia (2), Spain (6), Switzerland (4), and the United Kingdom (4). Eligible were male or female CKD5 adult (age $\geq 18$ ) patients on haemodialysis of original or grafted kidneys; diagnosed with renal anaemia; and treated with intravenous Binocrit ${ }^{\circ}$. The overall study methodology has been detailed elsewhere [17]. The original DOPPS methodology to estimate life-years gained from modifiable haemodialysis practices [2], as well as the methodology of the four country replications [13-16] and the MONITOR-CKD5 analyses are summarized in Table 1.

\section{Definition and Selection of Target Ranges for Modifiable Practices}

We used the same target ranges set forth in the 2004 DOPPS analysis [2] for dialysis dose ( $\mathrm{Kt} / \mathrm{V} \geq 1.2)$, phosphate control (serum phosphate $\leq 5.5 \mathrm{mg} / \mathrm{dL}$ ), and fluid management (interdialytic weight gain $\leq 5.7 \%$ ). For partial correction of serum albumin, we applied the range used in the Belgian [13], Spanish [14], and French [15] replications $(\geq 4.0 \mathrm{~g} / \mathrm{dL})$. Best practice guidelines for anaemia management have changed since 2004 with more conservative haemoglobin targeting and individualized risk-based dosing of erythropoiesis-stimulating agents [5, $18,19]$. Hence, the original [2] haemoglobin target of $\geq 11 \mathrm{~g} / \mathrm{dL}$ was reduced to $\geq 10 \mathrm{~g} / \mathrm{dL}$ in our analysis. For the evaluation of catheter use for vascular access, all DOPPS-based analyses [2, 13-16] used a facility-level variable (percentage of catheter use at the centre-level). In the MONITOR-CKD5 study, vascular access was not collected as a facility-level but as a dichotomous patientlevel variable. Some centres contributed small numbers of patients, hence determining centre percentages would have been subject to bias.

\section{Estimation of "Out of Range"}

Table 2 presents the recommended targets for each modifiable factor for the original DOPPS study [2] and the replication studies [13-16] and the percentage of each study sample outside the target range. We calculated the valid percentages of patients outside the indicated range for the MONITOR-CKD5 evaluable sample $(n=2023)$.

\section{Selection of Mortality Relative Risk Values}

In MONITOR-CKD5 patients were followed for up to 24 months, which is shorter than in DOPPS. Per expert opinion, except for haemoglobin and catheter use, we adopted the mortality $R R$ values generated by the five country-specific analyses (Table 2) [2,13-16] based on congruence in definition of target range between the MONITOR-CKD5 and these studies, and similarities in population. Due to guideline-recommended changes in $\mathrm{Hb}$ targets since 2004, the RR of 1.22 associated with $\mathrm{Hb}<10 \mathrm{~g} / \mathrm{dL}$ reported by Locatelli et al. was utilized [20]. This is an estimate adjusted for age, gender, comorbidities, mobility, malnourishment, ability to eat independently, years with end-stage renal disease (ESRD), country, and facility. Since MONITOR-CKD5 study measured catheter use at the patient level, the mortality RR adopted for this parameter was based on findings from a patient-level analysis of mortality risk associated with vascular access from DOPPS [21]; this estimate was adjusted for age, gender, race, years with ESRD, body weight, and comorbidities to reduce treatment-by-indication bias.

\section{Population Estimation}

Haemodialysis prevalent and incident counts for the 10 countries in MONITOR-CKD5 are presented in Table 3. Data for 7 of the 10 countries were obtained from the 2014 ERA-EDTA Registry Annual Report [22] Slovenia was included in the 2013 [23] but not the 2014 ERAEDTA Report; hence, 2013 data were utilized. Neither Germany nor Italy are included in the ERA-EDTA Registry. The most recent and sufficiently detailed data from their respective national databases were used instead, which were 2006 data for Germany [24] and 2013 data for Italy [25]. Country-level prevalent and incident counts were extrapolated from year of data to 2017 using an annual growth rate of $5 \%$. However, this growth rate was not included in the calculation of projected life-years over the 5 years, thus providing a conservative, lower-bound estimation of life-years gained.* Patients younger than 20 years of age are not reported ${ }^{1}$ ERA-EDTA Registry: Annual Report 2014 [22] ${ }^{2}$ Computed from 2006 dialysis prevalence (808 pmp X 95.2\%HD) and incidence (213 pmp X 92.6\%HD) rates from Nierenersatztherapie in Deutschland: Bericht über Dialysebehandlung und Nierentransplantation in Deutschland 2006-2007 [24] and 2006 population data $(82,437,995)$ from Eurostat (http:// ec.europa.eu/eurostat/) ${ }^{3}$ Computed from 2013 dialysis prevalence (760 pmp X 90.4\%HD) and incidence (160 pmp $\mathrm{X}$ 86.3\%HD) rates from Registro Italiano Dialisi e Trapianto: Report 2011-2013 [25] and 2013 population data $(59,685,227)$ from Eurostat (http://ec.europa.eu/eurostat/) ${ }^{4}$ Prevalent count from ERA-EDTA Registry $2014^{1}$ (Section $B$, aggregated data), incidence not reported; incident count imputed as Poland's HD prevalent count $[19,345] \mathrm{X}$ average percentage of HD incident count/HD prevalent count of 9 countries with complete data $[0.2044]^{5}$ ERA-EDTA Registry: Annual Report 2013 [23]

\section{Calculation of Attributable Patient-Years}

We replicated the Port et al. [2] methodology for estimating potential life-years gained using the MONITOR-CKD5 


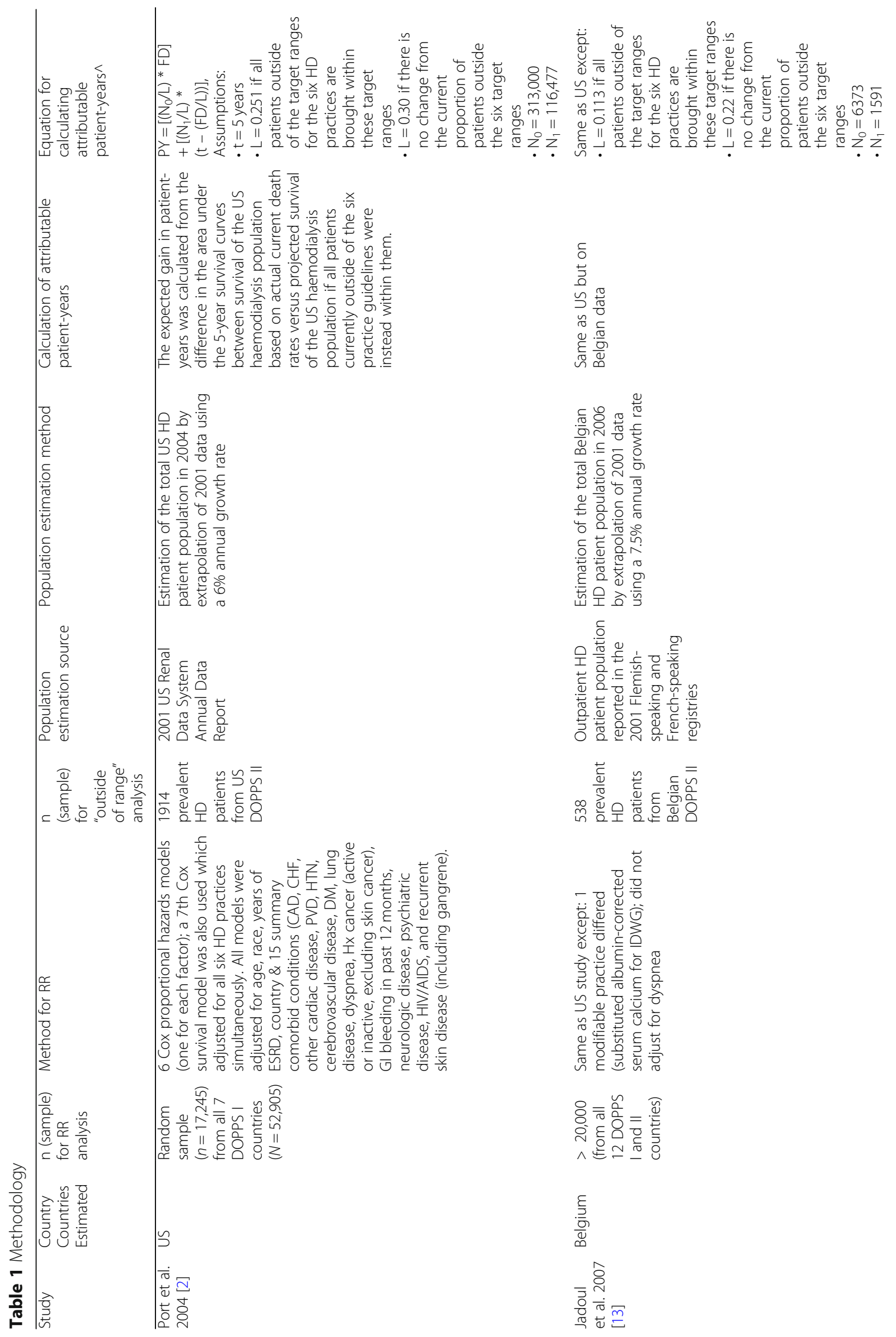




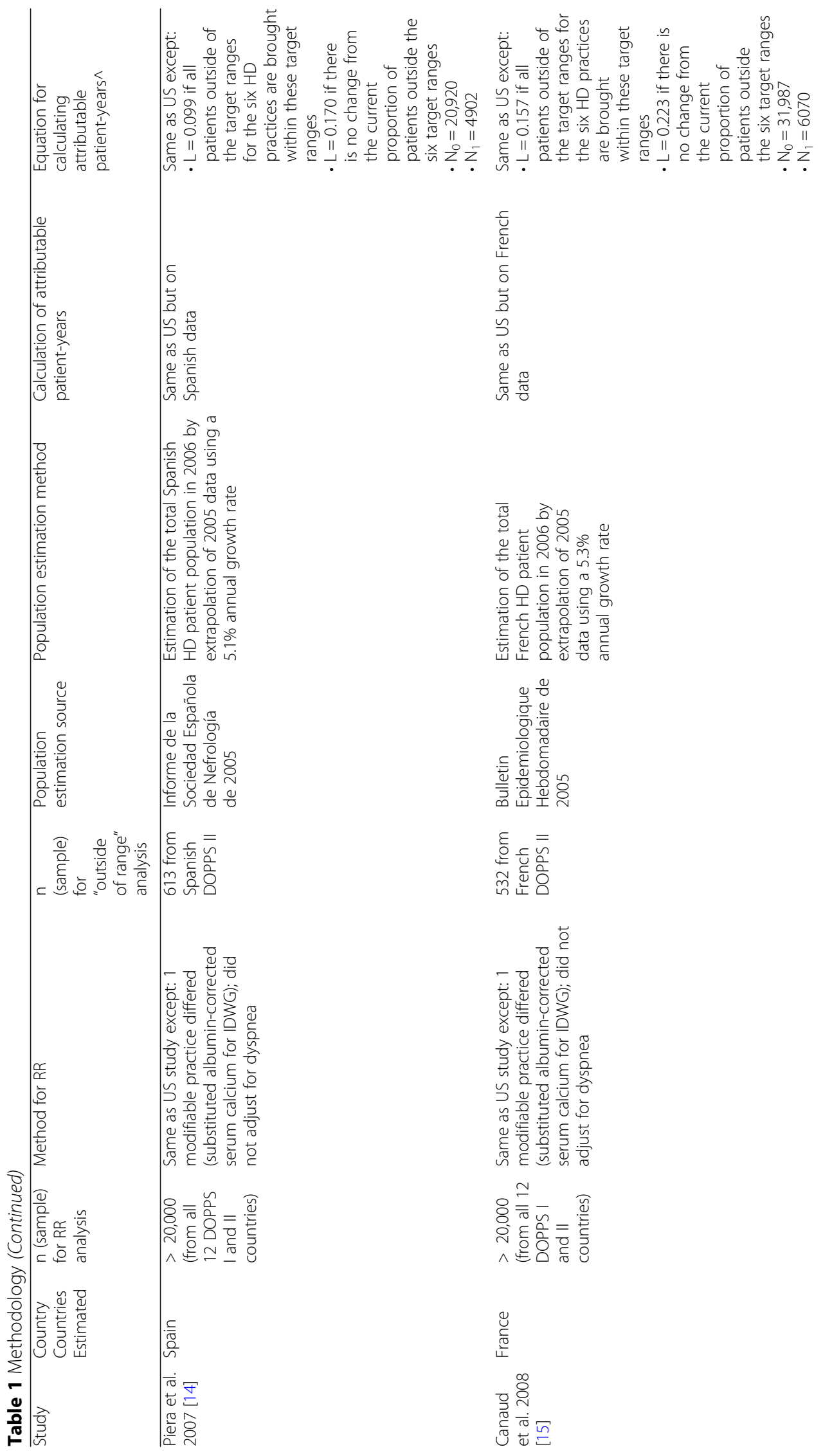




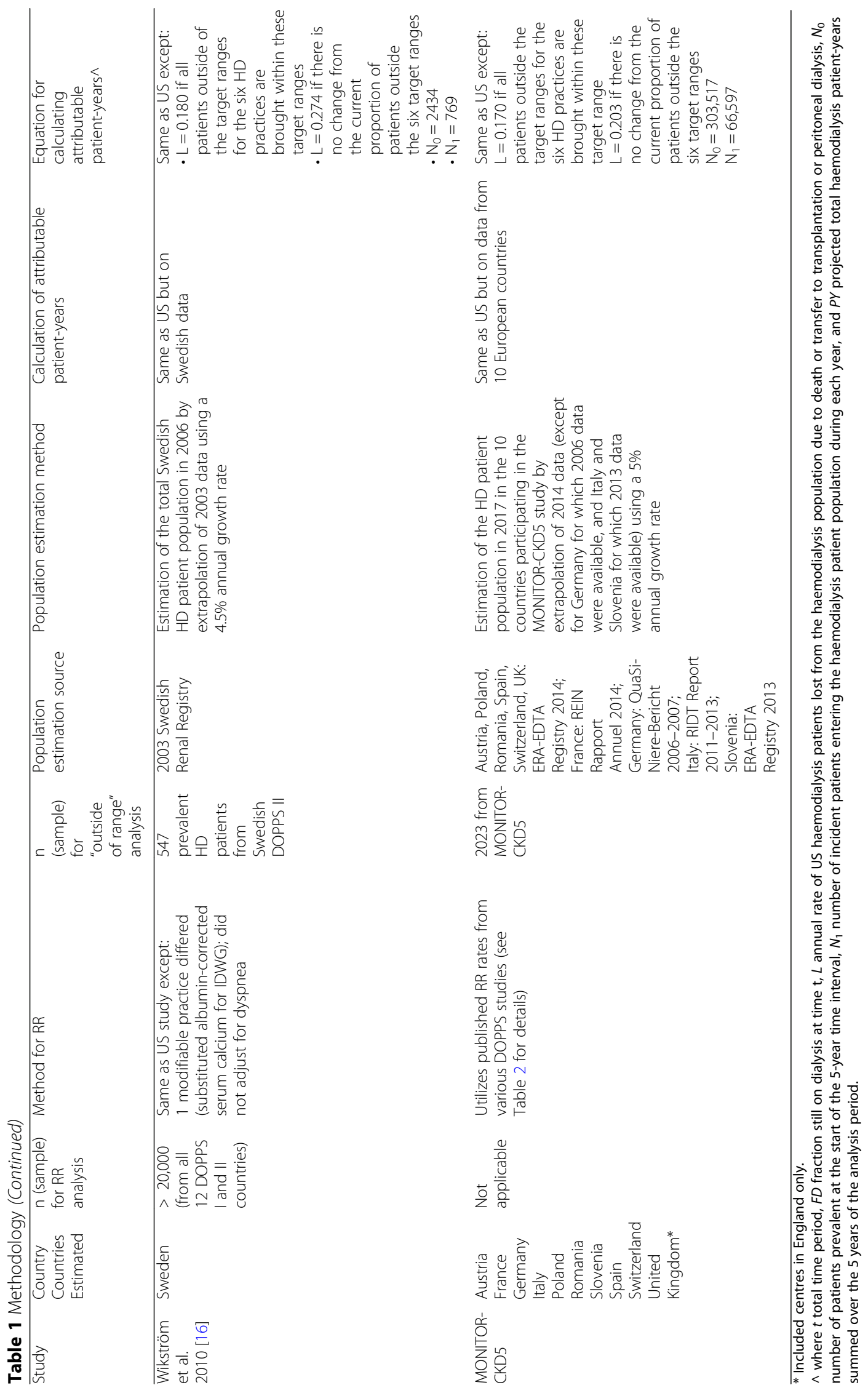




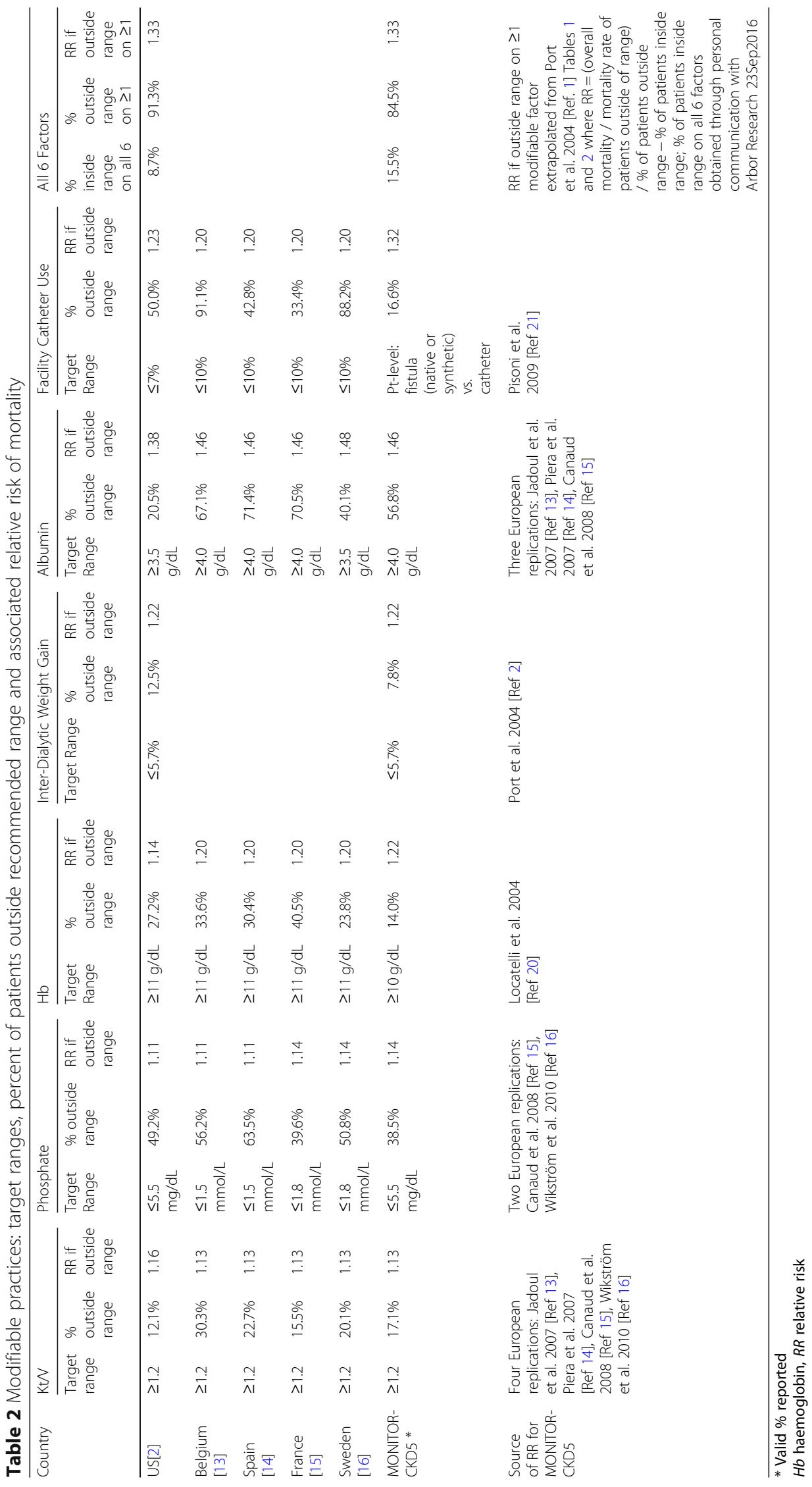


Table 3 Haemodialysis prevalent and incident counts

\begin{tabular}{|c|c|c|c|c|c|c|}
\hline \multirow[t]{2}{*}{ Countries } & \multirow[t]{2}{*}{ Source } & \multirow{2}{*}{$\begin{array}{l}\text { Year } \\
\text { of } \\
\text { Data }\end{array}$} & \multirow{2}{*}{$\begin{array}{l}\text { HD } \\
\text { Prevalent } \\
\text { Count }\end{array}$} & \multirow{2}{*}{$\begin{array}{l}\mathrm{HD} \\
\text { Incident } \\
\text { Count }\end{array}$} & \multicolumn{2}{|l|}{ Extrapolation to 2017} \\
\hline & & & & & HD Prevalent Count & HD Incident Count \\
\hline Austria & ERA-EDTA Registry $2014^{1}$ & 2014 & 3973 & 814 & 4599.24 & 942.31 \\
\hline France $^{\circ}$ & ERA-EDTA Registry $2014^{1}$ & 2014 & 41,314 & 8321 & $47,826.12$ & 9632.60 \\
\hline Germany & $\begin{array}{l}\text { Nierenersatztherapie in Deutschland } \\
2006-2007^{2}\end{array}$ & 2006 & 63,413 & 16,260 & $108,457.11$ & $27,809.96$ \\
\hline Italy & $\begin{array}{l}\text { Registro Italiano di Dialisi e Trapianto } \\
\text { Report 2011-2013 }\end{array}$ & 2013 & 41,006 & 8241 & $49,843.22$ & $10,017.40$ \\
\hline Poland + & $\begin{array}{l}\text { ERA-EDTA Registry } 2014^{1} \text { (Section B, } \\
\text { aggregated data) }\end{array}$ & 2014 & 19,345 & 3954 & $22,394.26$ & 4577.25 \\
\hline Romania $\wedge$ & ERA-EDTA Registry $2014^{1}$ & 2014 & 14,686 & 2538 & $17,000.88$ & 2938.05 \\
\hline Slovenia t† & ERA-EDTA Registry $2013^{5}$ & 2013 & 1349 & 209 & 1639.72 & 254.04 \\
\hline Spain & ERA-EDTA Registry $2014^{1}$ & 2014 & 21,517 & 4236 & $24,908.62$ & 4903.70 \\
\hline Switzerland & $\begin{array}{l}\text { ERA-EDTA Registry } 2014^{1} \text { (Section B, } \\
\text { aggregated data) }\end{array}$ & 2014 & 2636 & 663 & 3051.50 & 767.51 \\
\hline $\begin{array}{l}\text { United Kingdom, } \\
\text { England only }{ }^{\circ *}\end{array}$ & ERA-EDTA Registry $2014^{1}$ & 2014 & 20,556 & 4107 & $23,796.14$ & 4754.37 \\
\hline
\end{tabular}

- Incident counts are estimated (see ERA-EDTA Registry: Annual Report 2014 for methods[22])

+ Incidence data for Poland not reported; incident count imputed

$\wedge$ Overall prevalence of RRT is underestimated by approximately $3 \%$ due to an estimated $30 \%$ underreporting of patients living on a functioning graft

t+ Slovenia not included in ERA-EDTA Registry 2014, so 2013 ERA-EDTA data used[23]

$\sim$ Counts for Spain are sums of the following:

\begin{tabular}{|c|c|c|}
\hline Spain, Andalusia & 4115 & 795 \\
\hline Spain, Aragon ${ }^{\circ}$ & 529 & 105 \\
\hline Spain, Asturias ${ }^{\circ}$ & 447 & 93 \\
\hline Spain, Basque country & 789 & 159 \\
\hline Spain, Cantabria * & 196 & 43 \\
\hline Spain, Castile \& León ${ }^{* *}$ & 1078 & 217 \\
\hline Spain, Castile-La Mancha * & 826 & 196 \\
\hline Spain, Catalonia ${ }^{\circ}$ & 4227 & 889 \\
\hline Spain, Extremadura ${ }^{\circ}$ & 590 & 106 \\
\hline Spain, Galicia & 1540 & 292 \\
\hline Spain, Community of Madrid & 2576 & 593 \\
\hline Spain, Region of Murcia & 950 & 158 \\
\hline Spain, Navarre ${ }^{\circ *}$ & 251 & 61 \\
\hline Spain, Valencian region & 3403 & 529 \\
\hline
\end{tabular}

* Patients younger than 20 years of age are not reported

1 ERA-EDTA Registry: Annual Report 2014 [Ref 22]

${ }^{2}$ Computed from 2006 dialysis prevalence (808 pmp X 95.2\%HD) and incidence ( $213 \mathrm{pmp}$ X 92.6\%HD) rates from Nierenersatztherapie in Deutschland: Bericht über

Dialysebehandlung und Nierentransplantation in Deutschland 2006-2007 [Ref 24] and 2006 population data (82,437,995) from Eurostat (http://ec.europa.eu/eurostat/)

${ }^{3}$ Computed from 2013 dialysis prevalence (760 pmp X 90.4\%HD) and incidence (160 pmp X 86.3\%HD) rates from Registro Italiano Dialisi e Trapianto: Report

2011-2013 [Ref 25] and 2013 population data (59,685,227) from Eurostat (http://ec.europa.eu/eurostat/)

${ }^{4}$ Prevalent count from ERA-EDTA Registry 2014 ' (Section B, aggregated data), incidence not reported; incident count imputed as Poland's HD prevalent count

[19,345] X average percentage of HD incident count/HD prevalent count of 9 countries with complete data [0.2044]

${ }^{5}$ ERA-EDTA Registry: Annual Report 2013 [Ref 23]

proportions of patients out of range for each practice, the current population statistics for the 10 countries in the study, and the published relative risks associated with each practice. Based on the estimated percentages of patients falling outside the target ranges of the six modifiable practices and the mortality risk associated with each, Port el al. extrapolated to the US haemodialysis population for a 5 -year period to quantify potential life-years gained [2].

Projections were obtained by computing the difference in the area under the 5-year survival curve between the general survival of haemodialysis patients based on the actual mortality rate and the estimated 
survival if patients outside targets were brought into target range on the six modifiable factors based. The projected total haemodialysis patient-years summed over the 5 years of the analysis period $P Y$ is defined as.

$P Y=\left[\left(N_{O} / L\right)\right.$ " FD $]+\left[\left(N_{1} / L\right)\right.$ * $\left.(t-(F D / L))\right]$ (Eq. 1$)$.

where $t$ is the total time period in years, FD the fraction still on dialysis at $t, L$ the annual rate of haemodialysis patients lost from the haemodialysis population due to death or transfer to transplantation or peritoneal dialysis, $N_{0}$ the number of patients prevalent at the start of the 5-year time interval, and $N_{1}$ the number of incident patients entering the haemodialysis population during each year. $P Y$ is calculated for status quo $\left(P Y_{0}\right)$, where none of the patients outside the target range are brought into compliance; for each modifiable factor $i$ assuming all patients are brought into compliance $\left(P Y_{i}\right.$ where $i=\mathrm{Kt} / \mathrm{V}$, phosphate, $\mathrm{Hb}$, interdialytic weight gain, albumin, AVF/graft); and for the condition that all patients are brought into compliance on all six factors $\left(P Y_{a}\right)$.

From Eq. 1, we estimated the potential patient-years gained over the 5-year time interval $\triangle P Y_{5}$, for a given modifiable factor and aggregated across all six factors, as the difference between $P Y_{O}$ (the projected total patient-years summed over 5 years) and the corresponding $P Y_{i}$ for the $i$ th factor or $P Y_{a}$ for the six factors aggregated; or.

$$
\begin{aligned}
& \triangle P Y_{5, i}=P Y_{O}-P Y_{i} \text { (Eq. 2). } \\
& \text { and } \\
& \triangle P Y_{5, a}=P Y_{O}-P Y_{a} \text { (Eq. 3). }
\end{aligned}
$$

\section{Ethics}

The MONITOR-CKD5 study protocol was approved by the ethical review committees of participating centres in accordance with national laws and regulations. Written informed consent was obtained from all participating patients.

\section{Consort}

N/A; this is not a clinical trial but a simulation study.

\section{Results}

\section{Patients}

A total of 2086 patients were enrolled yielding an evaluable enrolment sample of 2023 patients. Details of patient enrolment and disposition have been reported elsewhere [26] as have been centre-level and interim patient-level results [27]. Most patients (40.6\%) were treated in Germany, followed by Romania (18.6\%) and Italy (15.3\%), accounting together for $74.4 \%$ of the study population. The sample was predominantly male (59.3\%), virtually completely Caucasian (96.2\%), with median age of 68 years (range 20-93). Median time on dialysis was 2.1 years (range $0-$
35). Most patients (82.5\%) had been treated with another ESA at enrolment, therefore can be considered in the maintenance phase of renal anaemia management, and were switched to Binocrit ${ }^{\circ}$. Mean $( \pm \mathrm{SD}) \mathrm{Hb}$ at enrolment was $11.09( \pm 1.14) \mathrm{g} / \mathrm{dL}$ and $68.0 \%$ of patients had $\mathrm{Hb}$ values in the $10-12 \mathrm{~g} / \mathrm{dL}$ range.

In terms of the six modifiable factors, as can be calculated from Tables 2, 82.9\% were within target range for $\mathrm{Kt} / \mathrm{V}(\geq 1.2), 61.5 \%$ had adequate phosphate control (serum phosphate $\leq 5.5 \mathrm{mg} / \mathrm{dL}$ ), $86.0 \%$ had $\mathrm{Hb} \geq 10 \mathrm{~g} / \mathrm{dL}$, 92.2\% had interdialytic weight gain $\leq 5.7,43.2 \%$ had partial correction of serum albumin $(\geq 4.0 \mathrm{~g} / \mathrm{dL})$, and $83.4 \%$ had vascular access via either an arteriovenous fistula or graft.

\section{Estimated Patient Life-Years Gained}

Table 4 summarizes the patient life-years gained over five years, estimated per Eqs. 1 through 3 above, if respectively an optimal 100\% (or suboptimal 50\%) of patients falling outside of the recommended target range on the six modifiable practices were brought into compliance. Results are reported for each modifiable factor separately, as well as for all 6 factors combined. The baseline for the 10 MONITOR-CKD5 countries is the estimated 303,517 haemodialysis patients for 2017 . This baseline is adjusted upward for the estimated 66,597 incident cases added over the 5-year period, adjusted downward for the variable annual death rate in general and associated with compliance with each factor, and further adjusted downward for the fixed annual loss rate to peritoneal dialysis or transplant.

The estimated potential patient-years gained over the 5 -year period at status quo $\left(P Y_{0}\right)$ is $1,563,221$. At the singular modifiable factor level, bringing all patients into Kt/V compliance yields 9319 additional patient-years over $P Y_{O}$ (for a total of 1,572,540); into phosphate compliance an additional 22,052 patient-years $(1,585,273)$; into $\mathrm{Hb}$ compliance an additional 12,826 patient-years $(1,576,047)$; into interdialytic weight gain compliance an additional 7222 patientyears $(1,570,443)$; into albumin compliance an additional 92,344 patient-years $(1,655,565)$; and into vascular access compliance an additional 21,746 patient-years $(1,584,967)$. On the aggregate, bringing all patients into compliance on all six modifiable factors results in an incremental gain of 97,428 patient-years for a total of $1,660,650$ patient-years (note that years gained if all 6 factors in target range is less than the sum of the years gained on the 6 individual factors since the modifiable practices are not mutually exclusive; i.e. patients can be outside target range on $\geq 1$ factor).

\section{Discussion}

Using as baseline the estimated 303,517 haemodialysis patients estimated to be alive in 2017 in the 10 European countries that participated in the MONITOR-CKD5 
Table 4 Project patient-years gained based on relative risk for compliance with recommended targets (over 5 years)

\begin{tabular}{|c|c|c|c|c|c|c|c|c|}
\hline Measure & $\begin{array}{l}\text { Current } \\
\text { statistics }\end{array}$ & $\begin{array}{l}\mathrm{Kt} / \mathrm{N} \geq \\
1.2\end{array}$ & $\begin{array}{l}\text { Phosphate } \leq \\
5.5 \mathrm{mg} / \mathrm{dL}\end{array}$ & $\begin{array}{l}\mathrm{Hb} \geq 10 \\
\mathrm{~g} / \mathrm{dL}\end{array}$ & $\begin{array}{l}\text { IDWG } \leq \\
5.7 \%\end{array}$ & $\begin{array}{l}\text { Albumin } \geq \\
4.0 \mathrm{~g} / \mathrm{dl}\end{array}$ & $\begin{array}{l}\text { AVF or graft } \\
\text { V. catheter }\end{array}$ & All 6 Factors \\
\hline Annual death rate & $0.150^{1}$ & $0.1467^{2}$ & $0.1423^{2}$ & $0.1455^{2}$ & $0.1475^{2}$ & $0.1189^{2}$ & $0.1424^{2}$ & $0.1173^{2}$ \\
\hline $\begin{array}{l}\text { Annual rate of } \\
\text { other loss }\end{array}$ & 0.053 & 0.053 & 0.053 & 0.053 & 0.053 & 0.053 & 0.053 & 0.053 \\
\hline L (Total loss rate) & 0.203 & 0.200 & 0.195 & 0.199 & 0.200 & 0.172 & 0.195 & 0.170 \\
\hline $\mathrm{T}$ & 5 & 5 & 5 & 5 & 5 & 5 & 5 & 5 \\
\hline $\mathrm{N}_{0}{ }^{4}$ & 303,517 & 303,517 & 303,517 & 303,517 & 303,517 & 303,517 & 303,517 & 303,517 \\
\hline $\mathrm{N}_{1}{ }^{5}$ & 66,597 & 66,597 & 66,597 & 66,597 & 66,597 & 66,597 & 66,597 & 66,597 \\
\hline FD & 0.63760 & 0.63164 & 0.62343 & 0.62938 & 0.63298 & 0.57668 & 0.62363 & 0.57321 \\
\hline PY & $1,563,221$ & $1,572,540$ & $1,585,273$ & $1,576,047$ & $1,570,443$ & $1,655,565$ & $1,584,967$ & $1,660,650$ \\
\hline \multicolumn{9}{|l|}{$\begin{array}{l}\text { Potential patient } \\
\text { years gained }\end{array}$} \\
\hline $\begin{array}{l}\text { if } 100 \% \text { brought within } \\
\text { target }\end{array}$ & & 9319 & 22,052 & 12,826 & 7222 & 92,344 & 21,746 & $97,429^{6}$ \\
\hline $\begin{array}{l}\text { if } 50 \% \text { brought within } \\
\text { target }^{\text {Prg }}\end{array}$ & & 4501 & 10,651 & 6195 & 3488 & 44,601 & 10,503 & 47,057 \\
\hline \multicolumn{9}{|c|}{$\begin{array}{l}H b \text { haemoglobin, IDWG inter-dialytic weight gain, AVF arterio-venous fistula, } L \text { annual rate of US haemodialysis patients lost from the haemodialysis population } \\
\text { due to death or transfer to transplantation or peritoneal dialysis, } t \text { total time period, } N_{o} \text { number of patients prevalent at the start of the } 5 \text {-year time interval, } N_{1} \\
\text { number of incident patients entering the haemodialysis patient population during each year, } F D \text { fraction still on dialysis at time t, } P Y \text { projected total haemodialysis } \\
\text { patient years summed over the } 5 \text { years of the analysis period } \\
\text { From ERA-EDTA Registry: Annual Report 2014. Table B.6.7.a. Unadjusted 1-year survival (cohort 2008-2012): incident dialysis patients (from day 91). } \\
{ }^{2} \text { Mortality rate of pts. inside range = overall mortality / ((\% of patients outside range * RR) + } \% \text { of patients in range) } \\
{ }^{3} \text { Other loss to peritoneal dialysis or transplant assumed to be } 5.3 \% \\
{ }^{4} \mathrm{~N}_{0} \text { assumed to be } 303,517 \text { based upon population estimates for countries participating in MONITOR-CKD5 [Table 3] } \\
{ }^{5} \mathrm{~N}_{1} \text { assumed to be } 66,597 \text { based upon population estimates for countries participating in MONITOR-CKD5 [Table } 3 \text { ] } \\
{ }^{6} \text { Patient-years gained if all } 6 \text { factors in target range is less than the sum of the years gained on the } 6 \text { individual factors since the modifiable practices are not } \\
\text { mutually exclusive (i.e. patients can be outside target range on } \geq 1 \text { factor) } \\
{ }^{7} \text { Adjusted to } 0.4830 \text { of potential years gained if } 100 \% \text { brought within target (i.e. not } .50 \text {, due to results of sensitivity analysis; personal communication with Arbor Research) }\end{array}$} \\
\hline
\end{tabular}

study, and adjusting this upward for growth in this patient population and downward for mortality and transition to peritoneal dialysis or transplantation, we projected that the 5-year period starting in 2017 would yield a net total of $1,563,221$ patient-years under the haemodialysis practice patterns observed in the study. However, as the DOPPS investigators have shown for several countries [2, 13-16], mortality in haemodialysis patients could potentially be reduced and life expectancy increased by focusing on six modifiable factors: dialysis quality $(\mathrm{Kt} / \mathrm{V})$, managing phosphate, haemoglobin, and albumin levels, reducing interdialytic weight gain (or, alternately managing calcium), and minimizing catheter use for vascular access.

If all haemodialysis patients in the 10 MONITOR-CKD5 countries were brought into the target range of these six modifiable practice patterns, an additional 97,429 patient life-years would hypothetically be gained over the 5 -year period starting in 2017. This corresponds to a $6.2 \%$ increase in 5-year survival. In comparison, the corresponding rates from the country-specific DOPPS analyses of the modifiable practices are, in ascending order, $8.2 \%$ for the US, $13.1 \%$ for France, $14.7 \%$ for Spain, $17.8 \%$ for Sweden, and $22.5 \%$ for Belgium $[2,13-16]$. The differences in rates may be due to sample size. However, considering that these simulation analyses cover a time span of approximately 15 years, this variation in rates may also suggest significant improvements having been achieved in haemodialysis care over time [28]. Though we chose not to perform countryspecific analyses, with collectively $25.3 \%$ of MONITORCKD5 patients being treated in Central and Eastern European countries, our lower rate in life-years gained underscores the advances in the quality of haemodialysis care made across all European regions.

This is also evident from the loss rates used in the various analyses. Consistent with their time period and country, Port et al. [2] assumed a $24.0 \%$ annual death rate and $6.5 \%$ annual rate of other loss (transition or peritoneal analysis or transplantation), for a total loss rate of $30.5 \%$. In the four country-specific DOPPS analyses [13-16], the annual death rates ranged from 17.1 to $24.3 \%$, the annual other loss rates from a gain of $2.1 \%$ to a loss of $5.3 \%$, for total loss rates between 17.0 and $27.4 \%$ In our ten-country European analysis, these rates were $15.0 \%$ (death-related), $5.3 \%$ (other), and $20.3 \%$ (total).

With the historical trends of fewer patients outside of the recommended range on each of the modifiable practices and decreasing mortality rates in dialysis populations, there is a diminishing opportunity for further improvement and, hence, smaller gains in potential life 
years. Yet, there is still room for improvement. While the percentage of patients out of range have decreased across all six modifiable practices, only $15 \%$ of patients in the MONITOR-CKD5 study were in range on all six.

The historical differences are also evident at the level of the individual practice patterns. In the Port et al. [2] analysis, reducing catheter use was associated with the greatest gain in patient life-years (with the highest potential gains in the USA), followed by increasing serum albumin levels (a measure of nutritional status and inflammation), and phosphate control. In our analysis, the greatest gains in theoretical patient life-years were achieved by targeting patient's serum albumin level followed, remotely, by phosphate control and vascular access. In the country-specific DOPPS analyses (which did not include interdialytic weight gain but serum calcium level instead), albumin levels and catheter use were the modifiable factors that prevailed in impact, followed by calcium levels and, variably, phosphate and $\mathrm{Hb}$ levels. Despite these differences in rates, all analyses converged on the importance of bringing albumin levels into target range, assuring vascular access by means of fistula or graft, and mineral control. That dialysis quality contributed only modestly to survival in all analyses may reflect the longstanding acceptance of the Kt/V $\geq 1.2$ standard. One notable challenge for clinicians is that while serum albumin exerts the most influence on mortality in these models in terms of relative risk, it is perhaps the most resistant of the six practices to therapeutic intervention, since it is linked to different factors, mainly inflammation and nutritional status [29].

Mortality risks attributable to the six modifiable practice patterns have not been systematically evaluated in randomized controlled trials (RCT); though a RCT of an established practice such as dialysis quality of $\mathrm{Kt} / \mathrm{V} \geq 1.2$ versus $<1.2$ would be ethically untestable. Hence, estimating preventable mortality and associated life-years gained as a function of modifiable practices may be appropriate as secondary endpoints in randomized trials. Further, the role of patient adherence, in particular to dietary restrictions, phosphate binders, and dialysis regimen, should be examined in future studies [30-32].

Our analyses have limitations. Like DOPPS, MONITOR-CKD5 is a non-controlled study. The use of patient-level versus facility-level data for catheter use may introduce treatment-by-indication bias especially in terms of patient age, comorbid conditions, and disease severity. The adjusted mortality risk associated with patient-level vascular access data utilized in our study [21] reduced such confounding but some residual bias cannot be excluded. Countries in MONITOR-CKD5 differed in some of the modifiable practices MONITOR-CKD5 [28]. The estimation of life-years gained using the MONITOR-CKD5 aggregate sample may conceal specific countries where opportunities for larger gains exist. Not being part of the ERA-EDTA Registry, national reports were used for Germany and Italy. The MONITOR-CKD5 patient population was virtually Caucasian with minimal racial/ethnic variation.

\section{Conclusions}

Replicating and extending the DOPPS analyses [2, 13-16] to the population in MONITOR-CKD5, we estimated in this hypothetical simulation that bringing all haemodialysis patients of the countries included in this study within the target range of six modifiable practices would yield a $6.2 \%$ increase in patient life-years over 5 years. An additional 97,429 life-years might be gained if, in descending order of survival impact, haemodialysis patients could be maintained at albumin levels $\geq 4.0 \mathrm{~g} / \mathrm{dL}$ and phosphate levels $\leq 5.5 \mathrm{mg} / \mathrm{dL}$, have vascular access by means of fistula or graft, have haemoglobin maintained at $\geq 10 \mathrm{~g} / \mathrm{dL}$, receive dialysis at $\mathrm{Kt} / \mathrm{V} \geq 1.2$, and have their interdialytic weight gain limited to $\leq 5.7 \%$. It is reassuring that compared to the original DOPPS papers, potential gains linked to quality improvement have decreased, reflecting better achievement of recommended therapeutic goals.

\section{Additional file}

Additional file 1: Supplementary List of all Ethical Review Committees for MONITOR-CKD5. (DOCX $99 \mathrm{~kb}$ )

\section{Abbreviations}

AVF: Arteriovenous fistula; DOPPS: Dialysis Outcomes and Practice Patterns Study.; ESRD: End-stage renal disease.; Hb: Hemoglobin.; RR: Relative risk.; RCT: Randomized controlled trial.; SD: Standard deviation.

\section{Acknowledgements}

We thank Dr. Ron Pisoni of Arbor Research Collaborative for Health for his scientific advice on methodological aspects of this replication analysis.

\section{Availability of data and material}

The datasets used and/or analysed during the current study are available from the corresponding author on reasonable request.

\section{Funding}

The MONITOR-CKD5 study was funded by Hexal AG. Sponsor participated in the development of the protocol, the discussion of the results, and review of the manuscript for scientific content.

\section{Authors' contributions}

CC was responsible for the study design, data collection, interpretation of results, the writing, and final approval of the manuscript. JM was responsible for the study design, data collection, interpretation of results, the writing, and final approval of the manuscript. DG was responsible for the study design, data collection, interpretation of results, the writing, and final approval of the manuscript. FD was responsible for the study design, data collection, interpretation of results, the writing, and final approval of the manuscript. PZ was responsible for the study design, data collection, interpretation of results, the writing, and final approval of the manuscript. GL was responsible for the study design, data collection, interpretation of results, the writing, and final approval of the manuscript. KD was responsible for the study design, the statistical analysis, interpretation of results, the writing, and final approval of the manuscript. AK was responsible for the study design, interpretation of results, the writing, and final approval of the 
manuscript. IA was responsible for the study design, the statistical analysis, interpretation of results, the writing, and final approval of the manuscript. KM was responsible for the study design, the statistical analysis, interpretation of results, the writing, and final approval of the manuscript. All authors agree to be accountable for all aspects of the work.

\section{Ethics approval and consent to participate}

The MONITOR-CKD5 study protocol was approved by the ethical review committees of participating centres in accordance with national laws and regulations. The central ethical review committees included Ethics Committee of the Ärztekammer Nordrhein (Düsseldorf, Germany), Ethics Committee of the Hospital-University Policlinico-Vittorio Emanuele of Catania (Catania, Italy), Independent Bioethics Committee for Scientific Research at GU Med (Gdańsk, Poland), National Agency for Medicines and Medical Devices (Bucuresti, Romania), Institute of Clinical Neurophysiology, Clinical Center Ljubljana (Ljubljana, Slovenia), Health Counseling General Secretary of Quality and Modernization, Autonomic Committee of Clinical Trials (Sevilla, Spain), and Cambridgeshire 1 Research Ethics Commitee (Cambridge, England); a complete list of all review boards including local ethical review committees is available as a supplementary online file (i.e., "Additional file 1"). Written informed consent was obtained from all participating patients.

\section{Consent for publication}

Not applicable because this report does not contain data for individual patients.

\section{Competing interests}

$C C, J M, D G, F D, P Z$, and $G L$ received compensation from Hexal AG for their participation in the work reported here. AK is an employee of Hexal AG. KD, KM, and IA are affiliated with Matrix45; by company policy, they cannot hold equity in sponsor organizations and cannot receive direct personal benefits, financial or other, from sponsor organizations. Matrix45 provides similar services to other biopharmaceutical companies without exclusivity constraints.

\section{Publisher's Note}

Springer Nature remains neutral with regard to jurisdictional claims in published maps and institutional affiliations.

\section{Author details}

${ }^{1}$ Centre Hospitalier Universitaire de Bordeaux and Unité INSERM 1026, University of Bordeaux, Bordeaux, France. ${ }^{2}$ Friedrich Alexander Universität Erlangen-Nürnberg, Erlangen, Germany. ${ }^{3}$ Guy's and St Thomas' NHS Foundation Hospital, London, UK. ${ }^{4}$ DaVita Clinical Research Germany, Duesseldorf, Germany. ${ }^{5}$ Université de Grenoble, Grenoble, France. ${ }^{6}$ Centre Hospitalier F.H. Manhés, Fleury-Mérogis, France. ${ }^{7}$ Matrix45, Tucson, AZ, USA. ${ }^{8}$ Department of Public Health, University of Basel, Basel, Switzerland. ${ }^{9} \mathrm{Hexal}$ AG, Holzkirchen, Germany. ${ }^{10}$ University of Arizona College of Pharmacy and College of Medicine, Tucson, AZ, USA.

\section{Received: 10 September 2018 Accepted: 8 February 2019}

Published online: 05 March 2019

\section{References}

1. Young EW, Goodkin DA, Mapes DL, Port FK, Keen ML, Chen K, et al. The Dialysis Outcomes and Practice Patterns Study (DOPPS): An international hemodialysis study. Kidney Int. 2000;57(Suppl 74):S74-81.

2. Port FK, Pisoni RL, Bragg-Gresham JL, Satayathum SS, Young EW, Wolfe RA Held PJ. DOPPS estimates of patient life years attributable to modifiable hemodialysis practices in the United States. Blood Purif. 2004;22(1):175-80.

3. National Kidney Foundation: K/DOQI clinical practice guidelines for chronic kidney disease: evaluation, classification, and stratification. Am J Kidney Dis. 2002;39(2) Suppl 1:S1-266

4. Locatelli F, Bárány P, Covic A, De Francisco A, Del Vecchio L, Goldsmith D, et al. Kidney disease: Improving Global Outcomes guidelines on anaemia management in chronic kidney disease: a European Renal Best Practice position statement. Nephrol Dial Transplant. 2013;28:1346-59.

5. Kidney Disease: Improving Global Outcomes (KDIGO) Anemia Work Group KDIGO clinical practice guideline for anemia in chronic kidney disease. Kidney Int. 2012;Suppl 2(4):279-335.
6. Kidney Disease: Improving Global Outcomes (KDIGO) Work Group: 2012 clinical practice guideline for the evaluation and management of chronic kidney disease. Kidney Int. 2013;Suppl 3(1):1-150.

7. Kalantar-Zadeh $\mathrm{K}$, Regidor DL, Kovesdy CP, Van Wyck D, Bunnapradist S, Horwich TB, et al. Fluid retention is associated with cardiovascular mortality in patients undergoing long-term hemodialysis. Circulation. 2009;119(5):671-9.

8. Saran R, Bragg-Gresham JL, Rayner HC, Goodkin DA, Keen ML, van Dijk PC, et al. Nonadherence in hemodialysis: Associations with mortality, hospitalization, and practice patterns in the DOPPS. Kidney Int. 2003;64:254-62.

9. Combe C, Pisoni RL, Port FK, Young EW, Canaud B, Mapes DL, et al. Dialysis Outcomes and Practice Patterns Study: Données sur l'utilisation des cathéters veineux centraux en hémodialyse chronique. Nephrologie. 2001; 22:379-84.

10. Dhingra RK, Young EW, Hulbert-Shearon TE, Leavey SF, Port FK. Type of vascular access and mortality in U.S. hemodialysis patients. Kidney Int. 2001; 60:1443-51

11. Pisoni RL, Young EW, Combe C, Leavey SF, Greenwood RN, Hecking E, et al. Higher catheter use within facilities is associated with increased mortality and hospitalization. Results from the DOPPS. J Am Soc Nephrol. 2001;299A:12.

12. Grubbs V, Wasse H, Vittinghoff E, Grimes BA, Johansen KL. Health status as a potential mediator of the association between hemodialysis vascular access and mortality. Nephrol Dial Transplant. 2013;29(4):892-8.

13. Jadoul M, Lameire N, Bragg-Gresham JL, Eichleay MA, Pisoni RL, Port FK DOPPS estimate of patient life years attributable to modifiable haemodialysis practices in Belgium. Acta Clin Belg. 2007;62(2):102-10.

14. Piera L, Cruz JM, Braga-Gresham JL, Eichleay MA, Pisoni RL, Port FK. Estimación, según el estudio DOPPS, de los años de vida de pacientes atribuibles a las prácticas de hemodiálisis modificables en España. Nefrología. 2007;27(4):496-504.

15. Canaud B, Combe C, Bragg-Gresham JL, Eichleay MA, Pisoni RL, Port FK. Gain de vie potentiel pour les patients hémodialysés français attribuable aux modifications des pratiques et la mise en conformité avec les cibles recommandées: une estimation permise par l'étude DOPPS. Néphrol Thér. 2008:4(4):256-65.

16. Wikström B, Jacobson SH, Bragg-Gresham J, Eichleay M, Pisoni R, Port F. Dialysis Outcomes and Practice Patterns Study estimate of patient life-years attributable to modifiable haemodialysis practices in Sweden. Scand J Urol Nephrol. 2010;44(2):113-20.

17. Gesualdo L, London G, Turner M, Lee C, MacDonald K, Goldsmith D, et al. A pharmacoepidemiological study of the multi-level determinants, predictors, and clinical outcomes of biosimilar epoetin alfa for renal anaemia in haemodialysis patients: background and methodology of the MONITORCKD5 study. Intern Emerg Med. 2013;8(5):389-99.

18. National Kidney Foundation. KDOQI Clinical Practice Guideline and Clinical Practice Recommendations for Anemia in Chronic Kidney Disease: 2007 Update of Hemoglobin Target. Am J Kidney Dis. 2007;50(3):471-530.

19. Locatelli F, Aljama P, Canaud B, Covic A, De Francisco A, Macdougall IC, et al. Target haemoglobin to aim for with erythropoiesis-stimulating agents: a position statement by ERBP following publication of the Trial to Reduce Cardiovascular Events with Aranesp ${ }^{\circledast}$ Therapy (TREAT) Study. Nephrol Dial Transplant. 2010:25(9):2846-50.

20. Locatelli F, Pisoni RL, Combe C, Bommer J, Andreucci VE, Piera L, et al. Anaemia in haemodialysis patients of five European countries: association with morbidity and mortality in the Dialysis Outcomes and Practice Patterns Study (DOPPS). Nephrol Dial Transplant. 2004;19(1):121-32.

21. Pisoni RL, Arrington CJ, Albert JM, Ethier J, Kimata N, Krishnan M, et al. Facility hemodialysis vascular access use and mortality in countries participating in DOPPS: an instrumental variable analysis. Am J Kidney Dis. 2009;53(3):475-91.

22. ERA-EDTA Registry. Annual Report, vol. 2014. Amsterdam, The Netherlands: Academic Medical Center, Department of Medical Informatics; 2016.

23. ERA-EDTA Registry. Annual Report, vol. 2013. Amsterdam, The Netherlands: Academic Medical Center, Department of Medical Informatics; 2015.

24. Nierenersatztherapie in Deutschland. Bericht über Dialysebehandlung und Nierentransplantation in Deutschland, vol. 2006-2007. Berlin, Germany: QuaSi-Niere gGmbH; 2008. http://www.bundesverband-niere.de/fileadmin/ user_upload/QuaSi-Niere-Bericht_2006-2007.pdf. Accessed 04 Jul 2018

25. Registro Italiano Dialisi e Trapianto. Report 2011-2013. In: Società Italiana Nefrologia; 2017. http://www.ridt.sinitaly.org. Accessed 04 Jul 2018.

26. London G, Mann J, Goldsmith D, Combe C, Dellanna F, Zaoui P, et al. Long-term treatment with biosimilar epoetin-a (HX575) in hemodialysis 
patients with renal anemia: real-world effectiveness and safety in the MONITOR-CKD5 study. Clin Nephrol. 2018;89:109.

27. Gesualdo L, Combe C, Covic A, Dellana F, Goldsmith D, London G, et al. Risk-based individualisation of target $\mathrm{Hb}$ in haemodialysis patients with renal anaemia in the post-TREAT era: theoretical attitudes versus actual practice patterns (MONITOR-CKD5 study). Int Urol Nephrol. 2015;47:837-45.

28. Combe C, Covic A, Goldsmith D, Zaoui P, Gesualdo L, London G, et al. DOPPS-identified modifiable practices in haemodialysis (HD) patients in the European MONITOR-CKD5 (2010-12) study compared to DOPPS (2002-2003): significantly better quality of HD with disparities. Nephrol Dial Transplant. 2013;28(Suppl 1):244.

29. Kaysen GA. Serum albumin concentration in dialysis patients: Why does it remain resistant to therapy?: Management of comorbidities in kidney disease in the 21st century: Anemia and bone disease. Kidney Int. 2003;64:S92-8.

30. Karamanidou C, Clatworthy J, Weinman J, Horne R. A systematic review of the prevalence and determinants of nonadherence to phosphate binding medication in patients with end-stage renal disease. BMC Nephrol. 2008; 9(2, 1):-10.

31. Tonelli M, Pannu N, Manns B. Oral phosphate binders in patients with kidney failure. New Engl J Med. 2010;362(14):1312-24.

32. Cannata-Andia JB, Martin KJ. The challenge of controlling phosphorus in chronic kidney disease. Nephrol Dial Transplant. 2016;31:541-7.

Ready to submit your research? Choose BMC and benefit from:

- fast, convenient online submission

- thorough peer review by experienced researchers in your field

- rapid publication on acceptance

- support for research data, including large and complex data types

- gold Open Access which fosters wider collaboration and increased citations

- maximum visibility for your research: over $100 \mathrm{M}$ website views per year

At $\mathrm{BMC}$, research is always in progress.

Learn more biomedcentral.com/submissions 